\title{
Control of Pharmaceutical Cocrystal Polymorphism on Various Scales by Mechanochemistry: Transfer from the Laboratory Batch to the Large-Scale Extrusion Processing
}

\author{
Tomislav Stolar, ${ }^{\dagger}$ Stipe Lukin, ${ }^{\dagger}{ }^{\circ}$ Martina Tireli, $^{\dagger}$ Irena Sović, $^{\dagger}$ Bahar Karadeniz, $^{\dagger}$ Irena Kerekovic, \\ Gordana Matijašić, ${ }^{\S}$ Matija Gretić, ${ }^{\S}$ Zvonimir Katančic, ${ }^{\S}$ Igor Dejanovic, ${ }^{\S}$ Marco di Michiel,,$\|$ \\ Ivan Halasz, ${ }^{\dagger \odot}$ and Krunoslav Užarevíc ${ }^{*} \dagger \odot$ \\ ${ }^{\dagger}$ Division of Physical Chemistry, Ruđer Bošković Institute, Bijenička cesta 54, 10000 Zagreb, Croatia \\ ${ }^{\ddagger}$ University of Applied Health Sciences, Mlinarska cesta 38, HR-10000 Zagreb, Croatia \\ ${ }^{\S}$ University of Zagreb, Faculty of Chemical Engineering and Technology, Trg Marka Marulića 19, 10000 Zagreb, Croatia \\ "ESRF-European Synchrotron Radiation Facility, 71 Avenue de Martyrs, 38000 Grenoble, France
}

\section{Supporting Information}

\begin{abstract}
We demonstrate a controllable mechanochemical synthesis of cocrystal polymorphs of ascorbic acid (vitamin C) and nicotinamide (vitamin B3) on different scales and without using bulk solvents. Next to the previously described polymorph of the 1:1 cocrystal, which is one of the first cocrystals approved for human consumption, we report here a new, thermodynamically more stable polymorph detected during in situ synchrotron powder X-ray diffraction monitoring of milling reactions. The new polymorph is currently available exclusively by mechanochemical synthesis, and its crystal structure was determined from synchrotron

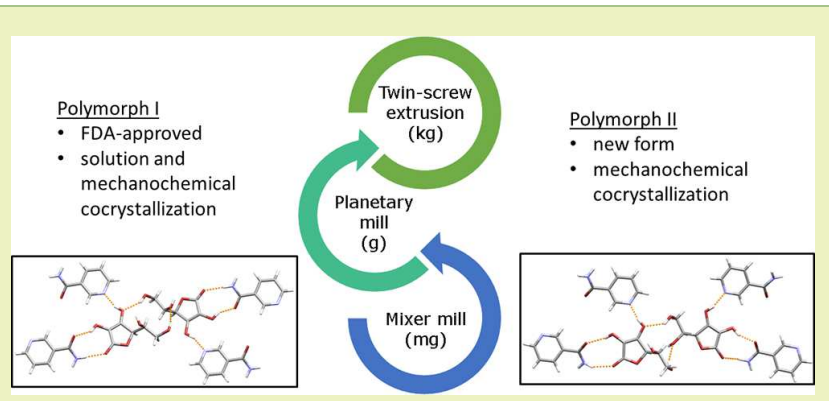
powder X-ray diffraction data. Laboratory in situ monitoring by Raman spectroscopy provided direct insight into the cocrystals formation and was further used to optimize the manufacturing procedure. Subgram synthesis using a laboratory mixer mill was transferred to the $10 \mathrm{~g}$ scale on a planetary ball mill and continuous manufacturing using a twin-screw extruder. Both cocrystal polymorphs perform excellently in tableting, thus alleviating the notoriously poor compactible properties of vitamin C, while the mechanochemical cocrystallization does not harm its antioxidant properties.
\end{abstract}

KEYWORDS: Mechanochemistry, Active pharmaceutical ingredients, Polymorphism control, Large-scale processing,

Twin-screw extrusion

\section{INTRODUCTION}

The use of mechanochemistry in modern materials chemistry continues to grow because of its efficiency, selectivity, and ecological suitability in obtaining the desired products. $^{1-4}$ Those characteristics go along with the increasing need to create more sustainable drug manufacturing processes, as has been stressed recently by the consortium of pharmaceutical companies. ${ }^{5}$ Mechanochemistry in the pharmaceutical industry is primarily used as a screening technique for solid forms of polymorphs, salts, and cocrystals of active pharmaceutical ingredients (APIs), ${ }^{6-9}$ but its role in the synthesis of APIs is becoming increasingly important. ${ }^{10-12}$ One way of transferring laboratory-scale mechanochemical production to larger manufacturing scales is utilizing twin-screw extrusion (TSE). ${ }^{13}$ TSE process is based on adding the reaction mixture through the feeder at one end, and two corotating screws are used for mixing, shearing, and conveying of the material that exits on the other end. TSE is used for the continuous production of a variety of chemicals, such as organics, ${ }^{14-16}$ metal-organic frameworks (MOFs), ${ }^{17,18}$ organic light-emitting diode (OLED) materials, ${ }^{19}$ and cocrystals. ${ }^{20-22}$

Cocrystallization is a convenient way of improving chemical and physical stability, ${ }^{23-25}$ compressibility $^{26}$ and bioavailability $^{27-30}$ of APIs. More than a decade of extensive research in the area of pharmaceutical cocrystals has shown that they offer enhanced API properties and more diverse space of solid forms for APIs that lack ionizable functional groups, which is a requirement for salt formation. ${ }^{31}$ Despite apparent advantages cocrystals may offer, their appearance on the market is still very scarce, $^{32}$ which is mainly up to their previous regulatory classification as well as manufacturing scale-up concerns. ${ }^{33}$ Latest US Food and Drug Administration (FDA) guidance for pharmaceutical industry states that from a regulatory perspective, a cocrystal of API and suitable coformer is 
considered analogous to a new polymorph of API. ${ }^{34}$ That means that API cocrystal is now in the same class as API polymorphs and salts. The expectations are that there will be a significant increase in API cocrystals becoming available on the market as evidenced by the recent commercialization of sacubitril-valsartan cocrystal drug by Novartis, branded as Entresto, to treat chronic heart failure. ${ }^{35}$

Vitamin $\mathrm{C}$ is common in pharmaceutical and food supplements industry and has the largest production among all vitamins, estimating 110 kilotons per year. ${ }^{36}$ One of the first cocrystals approved for human consumption by the FDA (21CFR172.315) is cocrystal of vitamin $\mathrm{C}(\mathrm{L}-(+)$-ascorbic acid, asc) and nicotinamide (a form of vitamin B3, na) as a formulation for inclusion into multivitamin preparations. ${ }^{37}$ It is known for this cocrystal (from now on I, Figure 1) to have

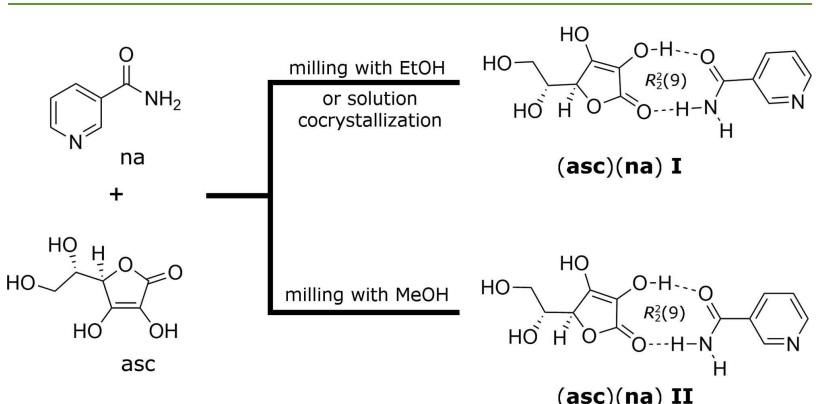

Figure 1. Molecular structures of nicotinamide (form of vitamin B3) and $\mathrm{L}-(+)$-ascorbic acid (vitamin $\mathrm{C}$ ) and the reaction conditions for the preparation of two polymorphs of (asc)(na) cocrystal.

antiscorbutic properties (prevention of scurvy) and certain activity against tuberculosis. ${ }^{38,39}$ It was recognized in the 1940 s, when in an attempt to prepare capsule of vitamin C with nicotinamide, authors observed its anomalous behavior and change of the reaction mixture color to yellow. ${ }^{40}$ Further study revealed that nicotinamide and vitamin $\mathrm{C}$ are forming 1:1 "addition compound," either by crystallization from ethanol $(\mathrm{EtOH})$ or by mechanical mixing and latter was patented by Gelatin Products Corporation. ${ }^{41}$ In 1949, Wenner ${ }^{42}$ identified this compound to be a molecular complex, not salt, which was confirmed almost 70 years later, after solving the structure of $\mathbf{I}$ in $2016 .^{43}$

Here, we report extensive research on the transfer of mechanochemical cocrystallization procedures to various scales, demonstrated on the reaction between asc and na (Figure 1). We used recently developed in situ monitoring of mechanochemical transformations ${ }^{44}$ by synchrotron powder $\mathrm{X}$ ray diffraction (PXRD), ${ }^{45-53}$ to detect the existence of a new, thermodynamically more stable cocrystal polymorph (asc)(na) II(from now on II, Figure 1). Laboratory monitoring of milling reactions using in situ Raman spectroscopy ${ }^{54}$ was further used to optimize the production procedures. For larger scales, we aimed to selectively prepare both cocrystal polymorphs on a 10 g scale via planetary ball milling and also to transfer these batch processes into a continuous TSE process on the industrial scale $(\sim 1 \mathrm{~kg} /$ hour rate). We solved the crystal structure of II from PXRD data and the slurry competition experiments were used to establish the thermodynamic relationship with $\mathbf{I}$. The direct tableting of cocrystal polymorphs prepared in the solid-state was assessed to try to account for poor tableting properties of vitamin C. $^{55-58}$

\section{EXPERIMENTAL SECTION}

Chemicals and Solutions. L-(+)-ascorbic acid $99+\%$ and nicotinamide $99 \%$ were purchased from Alfa-Aesar and used as received. For liquid-assisted grinding (LAG) experiments we used p.a. methanol $(\mathrm{MeOH})$ and p.a. EtOH from Kemika. ABTS $\left(\left(2,2^{\prime}\right.\right.$ azinobis(3-ethylbenzothiazoline-6-sulfonic acid)) was purchased from Sigma-Aldrich. $5 \mathrm{mM}$ solution of ABTS was prepared in $0.1 \mathrm{M}$ phosphate buffer, $\mathrm{pH}=7.4$. Trolox (6-hydroxy-2,5,7,8-tetramethychroman-2-carboxylic acid) was purchased from Sigma-Aldrich. A 5 $\mathrm{mM}$ solution of Trolox was prepared in ethanol. Phosphate buffer $(0.1$ $\mathrm{M}), \mathrm{pH}=7.4$, was prepared from disodium phosphate dihydrate and monosodium phosphate dihydrate purchased from Kemika. Potassium peroxydisulfate was purchased from Merck and $65 \mathrm{mM}$ solution was used. $5 \mathrm{mM}$ EtOH solutions of I (mechanochemical synthesis), II (mechanochemical synthesis), I (isolated from EtOH solution), L$(+)$-ascorbic acid, nicotinamide, and mixture of $\mathrm{L}-(+)$-ascorbic acid and nicotinamide were prepared in p.a. EtOH. All the chemicals were of analytical grade, and all solutions were prepared with ultrapure water from Millipore Milli-Q system (Milli-Q USA) if not stated otherwise.

Cocrystallization Experiments. Mechanochemical cocrystallization experiments by IST500 mixer mill (InSolido Technologies) were performed in $14 \mathrm{~mL}$ of poly(methyl methacrylate) (PMMA) jars using the same reaction conditions: $250 \mathrm{mg}$ overall mass of reactants in $1: 1$ stoichiometric ratio $(0.838 \mathrm{mmol}$ of asc and $0.838 \mathrm{mmol}$ of na), $20 \mu \mathrm{L}$ of appropriate liquid additive (if not stated otherwise), two stainless steel balls of $7 \mathrm{~mm}$ diameter as grinding media (each weighing $1.42 \mathrm{~g}$ ), $30 \mathrm{~Hz}$ grinding frequency, and $60 \mathrm{~min}$ grinding time. Solution cocrystallization experiments were done by dissolving $50 \mathrm{mg}$ of a solid mixture containing nicotinamide and L-(+)-ascorbic acid in 1:1 stoichiometric ratio $(0.168 \mathrm{mmol}$ of asc and $0.168 \mathrm{mmol}$ of $\mathbf{n a}$ ) in $0.5-1 \mathrm{~mL}$ of appropriate solvent.

Ten Gram Scale by Planetary Ball Milling. Planetary ball milling was performed by mixing $5.9 \mathrm{~g}$ of vitamin $\mathrm{C}$ and $4.1 \mathrm{~g}$ of nicotinamide in a $50 \mathrm{~mL}$ zirconia jar. EtOH $(0.8 \mathrm{~mL})$ or $\mathrm{MeOH}(1.6$ $\mathrm{mL}$ ) was added as the liquid additive, and four $10 \mathrm{~mm}$ zirconia balls were used as milling media. Reaction time was $60 \mathrm{~min}$ at $400 \mathrm{rpm}$.

Twin-Screw Extrusion. The continuous mechanochemical synthesis was carried out in Rondol $21 \mathrm{~mm}$ LAB TWIN corotating, intermeshing twin-screw extruder (TSE). All contact points were made of stainless steel. Total barrel length was $630 \mathrm{~mm}$, leading to $L /$ $D$ ratio of 30. Apart from forward-conveying sections, screws were equipped with three kneading blocks comprising $5 \mathrm{~mm}$ wide bilobed elements arranged in $30^{\circ}, 60^{\circ}$, and $90^{\circ}$ stagger angles with lengths of 65,25 , and $50 \mathrm{~mm}$, respectively. The barrel of the extruder consisted of five individual heating/cooling sections and was kept at $40{ }^{\circ} \mathrm{C}$ to ensure smooth screw rotation. For the purpose of this experiment, the die at the end of the extruder barrel was removed, and the extruded material was collected in a weighed beaker. Reactants were gently premixed in a beaker and fed manually through the first feed port. The screw speed was kept at $180 \mathrm{rpm}$, at which torque was kept at $90 \%$ of the maximum value, providing as high as possible throughput for the current screw configuration. To facilitate longer residence times and ensure higher conversion, the obtained product was fed through the extruder one more time.

Preparation of $\mathrm{ABTS}^{\bullet+}$. $\mathrm{The}^{\mathrm{ABTS}}{ }^{\bullet+}$ solution was prepared $24 \mathrm{~h}$ before spectroscopic measurement by mixing $0.5 \mathrm{~mL}$ of $65 \mathrm{mM}$ $\mathrm{K}_{2} \mathrm{~S}_{2} \mathrm{O}_{8}$ and $25 \mathrm{~mL}$ of $5 \mathrm{mM}$ ABTS prepared in $0.1 \mathrm{M}$ phosphate buffer, $\mathrm{pH}$ 7.4. ${ }^{59}$ The mixture was left in the dark at room temperature. For this study, the $\mathrm{ABTS}^{\bullet+}$ solution was diluted with $0.1 \mathrm{M}$ phosphate buffer, $\mathrm{pH} 7.4$, to an absorbance of $0.739 \pm 0.02$ at $734 \mathrm{~nm} . \mathrm{ABTS}^{\bullet+}$ is stable radical (radical was stable for more than 2 days when stored in the dark at room temperature).

Measurement of Antioxidant Activity. One milliliter of the $\mathrm{ABTS}^{\bullet+}$ solution was placed in $1.5 \mathrm{~mL}$ spectroscopic cuvette. After a steady state of absorbance (cca $1 \mathrm{~min}$ ) was reached, $5 \mu \mathrm{L}$ of measured sample, Trolox standard, or antioxidant solutions was added to the cuvette and mixed for $5 \mathrm{~s}$. The changes in absorbance were read after 1 and $4 \mathrm{~min}$. All determinations were carried out in triplicate. 
Characterization. X-ray powder diffraction data was collected on PANalytical Aeris diffractometer with $\mathrm{Ni}$-filtered $\mathrm{CuK}$ radiation, and with the $\mathrm{X}$-ray tube operating at $7.5 \mathrm{~mA}$ and $40 \mathrm{kV}$. Fourier-transform infrared attenuated total reflectance (FTIR-ATR) spectra were recorded on PerkinElmer SpectrumTwo spectrometer equipped with a diamond cell in the range of $4000-450 \mathrm{~cm}^{-1}$ and with a resolution of $4 \mathrm{~cm}^{-1}$.

Particle Size Distribution. The particle size distribution was obtained using laser diffraction analyzer SALD-3101 (Shimadzu, Japan) with measuring range from 0.3 to $3000 \mu \mathrm{m}$. Dry measuring unit was used and the samples were dispersed at 0.4 MPa. Presented particle size distribution is a mean value of three measurements.

Tableting. For the tableting process, $10 \mathrm{~g}$ of I and II obtained by planetary ball milling was used. Compression was performed using an eccentric single punch tableting machine TDP-5T (Zhejiang Wisely Machinery Co. Ltd., China) equipped with $8 \mathrm{~mm}$ round punches. All tablets were produced using equal compression force and $5 \mathrm{~mm}$ charging depth.

Surface Characterization of Tablets. Surface morphology of prepared tablets was examined using stereomicroscope SZX 16 (Olympus, Japan) at magnifications of $25 \times$.

In Situ Monitoring. PXRD monitoring of the milling reactions was performed in amorphous PMMA jars with two stainless steel balls as milling media at the European Synchrotron Radiation Facility (ESRF) in Grenoble, France, at ID15A beamline. For reactions, we used remotely operated IST500 (InSolido Technologies) mixer mill produced for this kind of measurements and operated at $30 \mathrm{~Hz}$. Beam energy was set to $69 \mathrm{keV}(\lambda=0.1797 \AA)$ to achieve the best possible resolution between diffraction peaks. X-ray beam was set to pass through the bottom of the jar and exposure time for each pattern was 5 s. Diffraction data were recorded on a Dectris Pilatus CdTe $2 \mathrm{M}$ detector positioned $730 \mathrm{~mm}$ from the sample, radial integration of the raw diffraction images was performed with an in-house Matlab script. Experimental hutch was air conditioned to $21{ }^{\circ} \mathrm{C}$. Laboratory in situ Raman spectroscopy was performed in the same experimental conditions using portable Raman system with OceanOptics Maya2000Pro spectrometer coupled with PD-LD (now Necsel) BlueBox laser source $(\lambda=785 \mathrm{~nm})$ with B\&W-Tek fiber optic Raman BAC102 probe. Raman probe was positioned $\sim 1 \mathrm{~cm}$ from the bottom of the jar and Raman spectra were collected as described previously. ${ }^{60}$

Analysis of Raman Spectra. First, PMMA jar contribution was subtracted from each spectrum, and remaining spectra were baseline corrected and normalized with the Euclidian norm. Details of the procedure can be found elsewhere. ${ }^{60}$ Spectra were arranged in a data matrix and subjected to the multivariate curve resolution-alternative least-squares (MCR-ALS) procedure to extract spectral and concentration profiles. ${ }^{61}$ Additional constraints, like closure and non-negativity in spectral and concentrations spectral contributions were used to obtain physically meaningful results. ${ }^{62}$ Additionally, spectra of pure components from the MCR-ALS procedure were compared to the actual Raman spectra of reactants, I and II. The spectrum of the unknown intermediate phase from MCR-ALS could not be obtained in pure form since it also contains the contributions from the reactants, I and II.

Crystallographic Section. Powder diffraction data for the crystal structure solution of II was collected in a capillary on a highresolution powder diffractometer at the 11-BM beamline of the Advanced Photon Source, Argonne National Laboratory, IL, USA, with a radiation wavelength of $0.457705 \AA$. The structure was solved by simulated annealing in direct space taking advantage of known molecular fragments of $\mathrm{L}-(+)$-ascorbic acid and nicotinamide which were treated independently as rigid bodies. Structure solution was recognized after meaningful networks of hydrogen bonding were formed. Structure refinement was finally performed on atoms using geometry restraints on bond distances and angles as well as planarity restraints on nicotinamide molecule. All calculations were performed using the program Topas. The CIF file, also containing the measured and calculated diffraction patterns, has been deposited with the Cambridge Crystallographic Data Centre (CCDC) under the deposition number 1883265 . These data can be obtained from the CCDC upon request.

\section{RESULTS AND DISCUSSION}

In Situ Mechanochemical Reaction Monitoring. We aimed to develop a mechanochemical procedure for the production of (asc)(na) cocrystal, both on the laboratory and multigram scale. As the mechanochemical reactivity significantly increases by the addition of liquids in liquid-assisted grinding (LAG), ${ }^{63-65}$ we tested several liquids as additives for milling reactions (Table S1 and Figure S1). Monitoring of the mechanochemical reaction between asc and na using $20 \mu \mathrm{L}$ of $\mathrm{EtOH}$ as the liquid additive revealed fast consumption of reactants and almost immediate occurrence of an intermediate, short-lived phase which was not possible to isolate as it occurs concomitantly with reactants and lives for $\sim 15 \mathrm{~min}$. The formation of known phase I (Figures 2 and 4a, 4c) started after $5 \mathrm{~min}$ and finished after $25 \mathrm{~min}$ of milling. We isolated $\mathbf{I}$ as the final product after $60 \mathrm{~min}$ of milling.

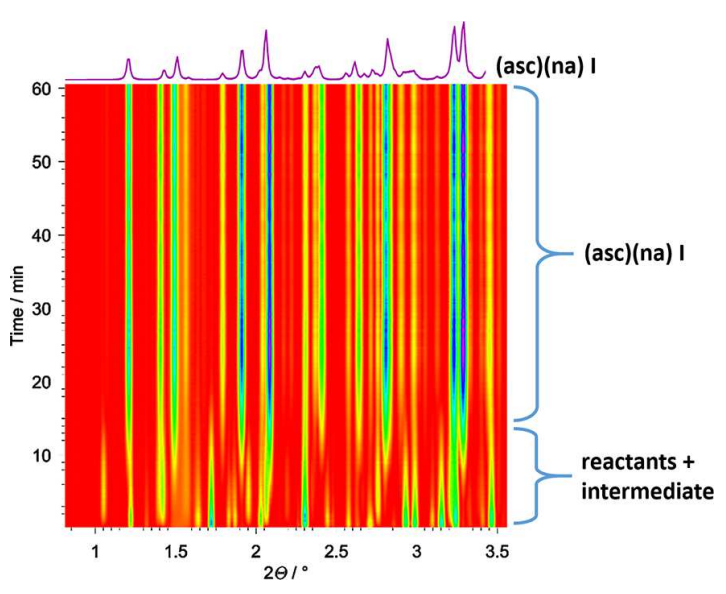

Figure 2. Time-resolved X-ray powder diffraction patterns of in situ monitoring of milling 1:1 reaction mixture of vitamin $\mathrm{C}$ and nicotinamide using ethanol as the liquid additive. Color code: Blue, high intensity; red, low intensity.

Switching to $\mathrm{MeOH}$ additive induced a change in the reaction pathway. Milling the reaction mixture of asc and na with $20 \mu \mathrm{L}$ of $\mathrm{MeOH}$ revealed the fast occurrence of the same intermediate phase that lived concomitantly with reactants for approximately $3 \mathrm{~min}$. Formation of $I$ is finished after $9 \mathrm{~min}$ of milling. Further milling resulted in the occurrence of a new phase, II, which started to form after $20 \mathrm{~min}$ and with the simultaneous diminishing of diffraction peaks of I (Figure 3). However, subsequent analysis of the final pattern collected after $90 \mathrm{~min}$ of milling revealed that the final product is a mixture of I and II (Figure S12).

Intermediate that can be seen in LAG with $\mathrm{EtOH}$ and $\mathrm{MeOH}$ does not appear in neat grinding (Figure S3). Therefore, it seems that its formation is favored only in LAG conditions.

To obtain only II, we increased the volume of added $\mathrm{MeOH}$ to $40 \mu \mathrm{L}$ since the liquid additive volume can have a substantial effect on the reaction outcome. ${ }^{66,67}$ In situ Raman monitoring of LAG reaction with $40 \mu \mathrm{L}$ of $\mathrm{MeOH}$ revealed much faster cocrystallization. Form I, which formed in first $10 \mathrm{~min}$ of milling, transformed to II as observed in LAG with $20 \mu \mathrm{L}$ of $\mathrm{MeOH}$, but this time the transformation was completed after 


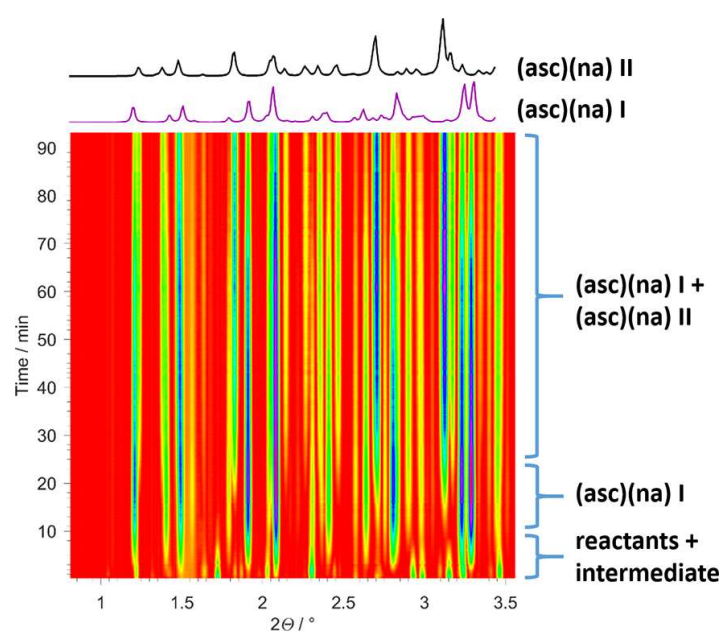

Figure 3. Time-resolved X-ray powder diffraction patterns of in situ monitoring of milling 1:1 reaction mixture of vitamin $C$ and nicotinamide using methanol as the liquid additive. Color code: blue, high intensity; red, low intensity.

40 min of milling (Figures $4 \mathrm{~b}$ and $4 \mathrm{~d}$ ). The final product was pure solid phase II, with FTIR-ATR and Raman spectrum similar to I (Figures S10 and S11).

Crystal Structure Studies. Crystal structure of II was solved from PXRD data (Figure 5) with crystallographic parameters as given in Table 1 .
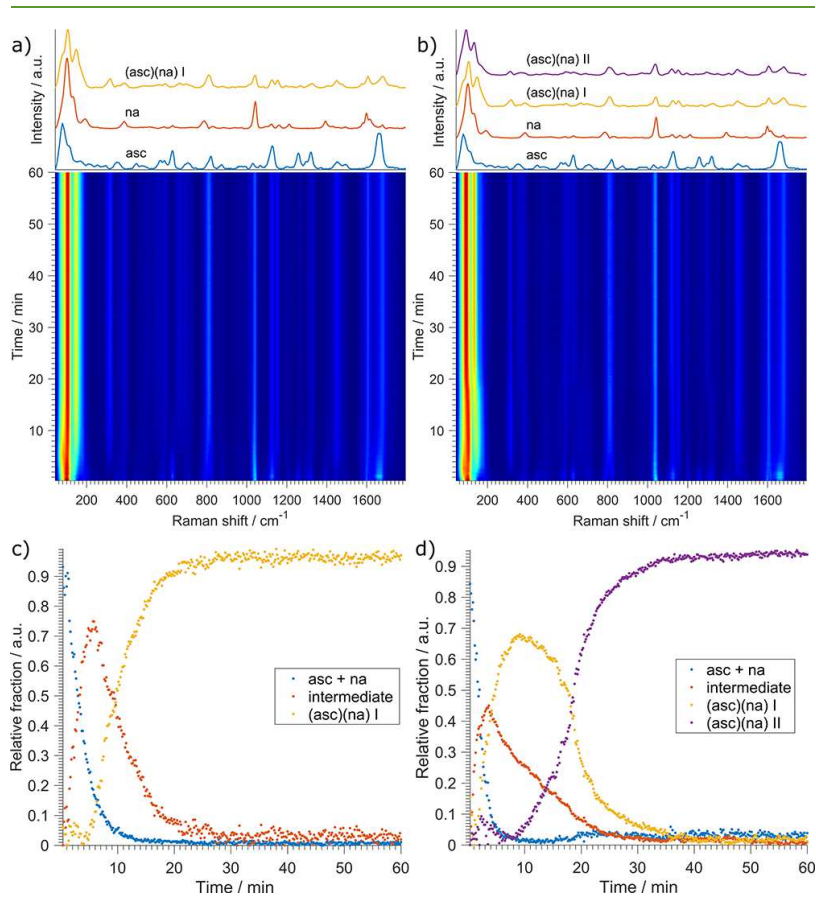

Figure 4. Time-resolved Raman spectra of in situ monitoring of milling 1:1 reaction mixture of vitamin $\mathrm{C}$ and nicotinamide using (a) ethanol and (b) methanol as the liquid additives. Color code: red, high intensity; blue, low intensity. Reaction profiles extracted with multivariate curve resolution alternative least-squares procedure from Raman monitoring of milling 1:1 reaction mixture of vitamin $\mathrm{C}$ and nicotinamide using (c) ethanol and (d) methanol as the liquid additives.

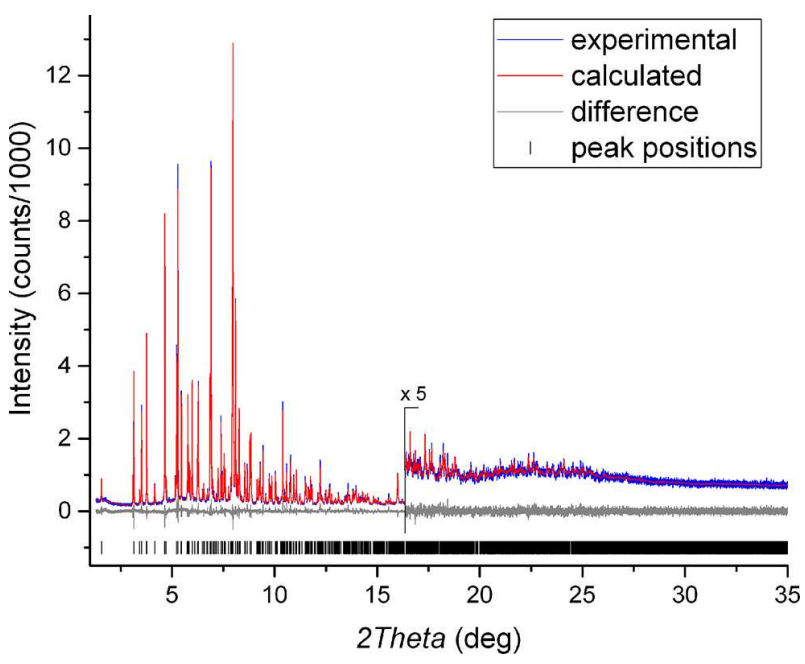

Figure 5. Rietveld fit for the refinement of the crystal structure of II. The high-angle region of the pattern is enlarged to reveal more detail. Radiation wavelength is $0.457705 \AA$.

Table 1. Crystallographic Data for II

$\begin{array}{ll}\text { molecular formula } & \mathrm{C}_{12} \mathrm{H}_{14} \mathrm{~N}_{2} \mathrm{O}_{7} \\ \text { formula weight }\left(\mathrm{g} \mathrm{mol}^{-1}\right) & 298.28 \\ \text { space group } & P 2_{1} \\ a(\AA) & 7.749926(33) \\ b(\AA) & 33.38721(15) \\ c(\AA) & 5.081955(22) \\ \alpha(\mathrm{deg}) & 90 \\ \beta(\mathrm{deg}) & 99.13411(28) \\ \gamma(\mathrm{deg}) & 90 \\ V\left(\AA^{3}\right) & 1298.2735(99) \\ \mathrm{Z} & 4 \\ \text { temperature }(\mathrm{K}) & 298 \\ \text { radiation type } & \text { synchrotron } \\ \text { wavelength }(\AA) & 0.457705 \\ R_{p} & 0.049 \\ R_{w p} & 0.062 \\ \mathrm{GOF} & 1.17 \\ R\left(F^{2}\right) & 0.022\end{array}$

Both polymorphs crystallize in chiral space groups, I in the triclinic $P 1$ and II in the monoclinic $P 2_{1}$ space group. Asymmetric units of both polymorphs contain two molecules of asc and na. They both exhibit very similar intermolecular and crystal packing interactions characterized by chains of hydrogen bonding interactions and by a ring $R_{2}^{2}(9)$ heterosynthon in which one $-\mathrm{OH}$ group of asc forms a hydrogen bond with the $\mathrm{C}=\mathrm{O}$ group of na, while the $\mathrm{C}=\mathrm{O}$ group of asc forms a hydrogen bond with the $-\mathrm{NH}_{2}$ group of na(Figure $6 \mathrm{a}$ and $6 \mathrm{~b}) .{ }^{68}$ Network of hydrogen bonds further assembles into layers (Figure $6 \mathrm{c}$ and $6 \mathrm{~d}$ ).

Solution Screening and Relative Stability Measurements. After obtaining two polymorphs mechanochemically, for comparison, we also performed solution cocrystallization. We dissolved mixtures containing asc and na in different solvents (Table S2 and Figure S1) allowing for full solvent evaporation, and isolated yellow precipitates. As evidenced from the PXRD data, solution cocrystallizations resulted exclusively in I, even when the bulk solvent was $\mathrm{MeOH}$, which is in agreement with the literature. ${ }^{69}$ As opposed to LAG 

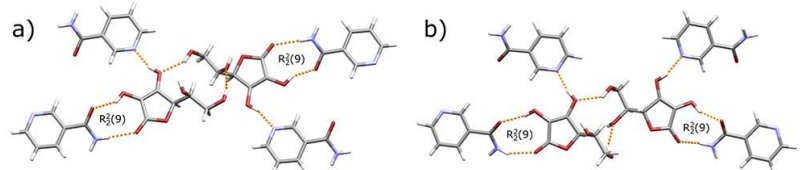

c)

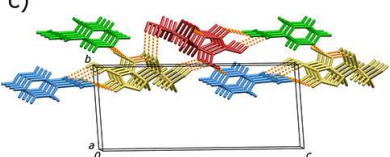

d)

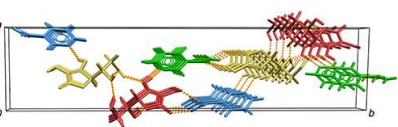

Figure 6. Hydrogen bonding motives in (a) I and (b) II. Both structures exhibit similar hydrogen bonding interactions and are stabilized by $R_{2}{ }^{2}(9)$ supramolecular synthon between asc and na molecules. Hydrogen bonded networks form layers in (c) I and (d) II.

experiments, where the addition of water resulted in the formation of pure II (Figure S1) but with nonhomogeneous distribution of milled solid (Figures S2 and S4), attempt to crystallize product from water resulted only in brown glutinous solution which darkened over time, without any crystals occurrence.

The thermodynamic relationship between polymorphs was determined in the slurry experiments in acetonitrile, in which both polymorphs have low solubility, and at room temperature. Equal amounts of both polymorphs were stirred in acetonitrile for $24 \mathrm{~h}$, after which the solid in the slurry was carefully isolated and dried in air. PXRD data revealed that the dried sample was pure II, revealing the complete transformation of I to a more thermodynamically stable II (Figure S6). Results from the slurry experiments are in agreement with Ostwald's rules of stages: ${ }^{70}$ less thermodynamically stable I appears first and then transforms to II upon continued milling (Figure 4d). Both polymorphs are however bench-stable for at least six months (Figure S7).

Scaling up Manufacturing Processes for Both Cocrystal Polymorphs. Scaling up mechanosynthesis of both polymorphs to $10 \mathrm{~g}$ has been achieved with the planetary mill. We used TSE for solid-state flow synthesis on a $100 \mathrm{~g}$ test scale. For $10 \mathrm{~g}$ scale, we used Fritsch Pulverisette 6 planetary mill operating at $400 \mathrm{rpm}$, and zirconia milling equipment to avoid pollution of products. Transfer of mixer mill to planetary mill synthesis was successful for both polymorphs, and both $\mathrm{MeOH}$ and $\mathrm{EtOH}$ additives resulted in the quantitative formation of target polymorph form after $60 \mathrm{~min}$ of milling (Figure S8).

For TSE experiments, we used Rondol $21 \mathrm{~mm}$ LAB TWIN extruder with $630 \mathrm{~mm}$ long barrel and five individual heating sections (Figure 7). We premixed asc and na in a glass beaker before started to adding it carefully through the feeder, and 40 $\mathrm{mL}$ of $\mathrm{EtOH}$ or $\mathrm{MeOH}$ were added through the adjacent inlet for approximately $110 \mathrm{~g}$ of the reaction mixture. As a standard TSE procedure, the obtained mixture was fed through the extruder one more time to ensure the better transformation of reactants to the desired product. In the same manner as on the laboratory scale, selective synthesis and polymorphism could be controlled even during the continuous manufacturing process (Figure S9). Rietveld analysis of the extrusion products showed some excess of reactants in case of I (Figure S13), whereas we obtained phase pure II (Figure S14). At the screw speed of $180 \mathrm{rpm}$, the accomplished throughput was in the range of $21-23 \mathrm{~g} / \mathrm{min}$ for each extrusion cycle. As for the space-time yield (STY) for these three different reactors, mixer mill provided the lowest STY of $440 \mathrm{~kg} \mathrm{~m}^{-3} \mathrm{~d}^{-1}$, whereas the

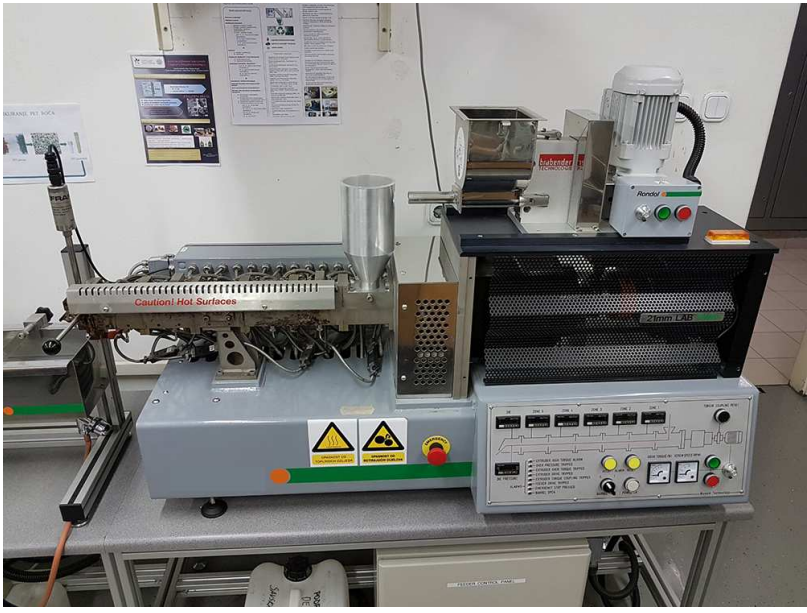

Figure 7. Twin-screw extruder used for the continuous synthesis of (asc)(na) polymorphs. All contact points are made of stainless steel.

use of planetary mill significantly increased the STY to $4800 \mathrm{~kg}$ $\mathrm{m}^{-3} \mathrm{~d}^{-1}$. In accordance with recent reports, ${ }^{13-15}$ continuous processing by TSE resulted in orders of magnitude increase in STY, amounting to $\sim 324400 \mathrm{~kg} \mathrm{~m}^{-3} \mathrm{~d}^{-1}$.

Antioxidant Activity of Prepared Cocrystal Polymorphs. To test the effect of the mechanical action on the activity and quality of vitamin $\mathrm{C}$, we performed TEAC assay (Trolox equivalent antioxidant capacity), a standard test for estimation of activity of vitamin $\mathrm{C}$, which was first reported by N. J. Miller et al. $^{71}$ and later improved. ${ }^{72}$ TEAC is a measurement of antioxidant strength based on Trolox (6hydroxy-2,5,7,8-tetramethychroman-2-carboxylic acid) and expressed in Trolox Equivalents, estimated from the loss of color when antioxidant is added to the blue-green chromophore ABTS ((2,2'-azinobis(3-ethylbenzothiazoline-6-sulfonic acid)) radical cation $\left(\mathrm{ABTS}^{\bullet+}\right)$. The antioxidant reduces $\mathrm{ABTS}^{\bullet+}$ to ABTS causing decolorization (Figure S18). The Trolox equivalents were calculated by dividing the difference in absorbance of the sample $\left(\Delta \mathrm{A}=\mathrm{A}\left(\mathrm{ABTS}^{\bullet+}\right)-\mathrm{A}(\right.$ sample $\left.)\right)$ with the difference in absorbance of the Trolox $\left(\Delta \mathrm{A}=\mathrm{A}\left(\mathrm{ABTS}^{\bullet+}\right)\right.$ A(Trolox)).

For all measurements, $5 \mathrm{mmol}$ solutions were used. After 1 min, pure $\mathrm{L}-(+)$-ascorbic acid demonstrated the Trolox equivalent of $0.964 \pm 0.096$ (mean of three determinations \pm standard deviation.), that is, antioxidant activity is substantial as expected (Table 2). The nicotinamide demonstrated the low Trolox equivalent of $0.005 \pm 0.003$, revealing low antioxidant activity. I and II obtained by

Table 2. Trolox Equivalents after 1 and $4 \mathrm{~min}$ for L(+)-Ascorbic Acid, Nicotinamide, I (Planetary Ball Milling), II (Planetary Ball Milling), I (Solution Synthesis), and the Mixture of L-(+)-Ascorbic Acid and Nicotinamide

\begin{tabular}{lcc} 
& \multicolumn{2}{c}{ Trolox equivalent } \\
\cline { 2 - 3 } \multicolumn{1}{c}{ sample } & $1 \mathrm{~min}$ & $4 \mathrm{~min}$ \\
asc & $0.964 \pm 0.096$ & $0.965 \pm 0.089$ \\
na & $0.005 \pm 0.003$ & $0.009 \pm 0.005$ \\
I-mech & $0.481 \pm 0.050$ & $0.482 \pm 0.050$ \\
II-mech & $0.438 \pm 0.009$ & $0.440 \pm 0.008$ \\
I-solution & $0.485 \pm 0.048$ & $0.486 \pm 0.048$ \\
asc and na (1:1) mixture & $0.508 \pm 0.045$ & $0.510 \pm 0.050$
\end{tabular}


planetary ball milling displayed similar Trolox equivalents compared to I obtained from solution, amounting to $0.481 \pm$ $0.050,0.438 \pm 0.009$, and $0.485 \pm 0.048$, respectively. This activity, stemming from the lower quantity of vitamin $\mathrm{C}$ in cocrystal is similar to the blind probe solution, containing vitamin $\mathrm{C}$ and nicotinamide in similar quantities, which demonstrated the Trolox equivalent of $0.508 \pm 0.045$. After 4 min, the antioxidant activity of all samples was not significantly higher when compared to the one observed after $1 \mathrm{~min}$, which indicates fast reaction kinetics. These results confirm that the proposed milling procedures do not harm the antioxidant activity of vitamin $\mathrm{C}$.

Mechanical Properties and Particle Size Distribution of Cocrystal Polymorphs. Both (asc)(na) cocrystal polymorphs prepared on a $10 \mathrm{~g}$ scale in a planetary ball mill were tested for their compressibility in the tableting process without any additional particle size reduction. Before measurement and tableting, samples were separated using $1 \mathrm{~mm}$ sieve to remove larger chips of the material. Initially, we compared the particle size distribution of reactants, asc and na to obtained cocrystal polymorphs (Figures S15-S17). Pure asc has a very broad particle size distribution $(0.3-1000 \mu \mathrm{m})$, and most of the particles are in the range from 30 to $1000 \mu \mathrm{m}$, while na particles are in the range from 10 to $200 \mu \mathrm{m}$. Both initial samples have very poor flowability and compressibility, and it was not possible to obtain their tablets by direct tableting, as they clogged the tableting machine. Wide size distribution is preferable in tableting and results in better packaging of particles and tablet strength. Smaller particles have a dual role, filling the voids between particles and also act as glidant by sticking to the surface of bigger particles and improving powder flowability. ${ }^{73}$ Samples from extrusion are also characterized by a large ratio of big particles and large flakes, and these samples were unsuitable for tableting assessment without additional mechanical treatment. On the other hand, cocrystal polymorphs obtained from planetary ball mill displayed excellent flowability and compressibility. Both samples have a high content of smaller particles $(<10 \mu \mathrm{m})$, and similar particle size distribution (Figures S15 and S16). As evidenced from tablet stereomicrographs, tablets of both cocrystal polymorphs have a smooth surface (Figure 8a and 8 b). Both samples were compressed at $5 \mathrm{~mm}$ charging depth,

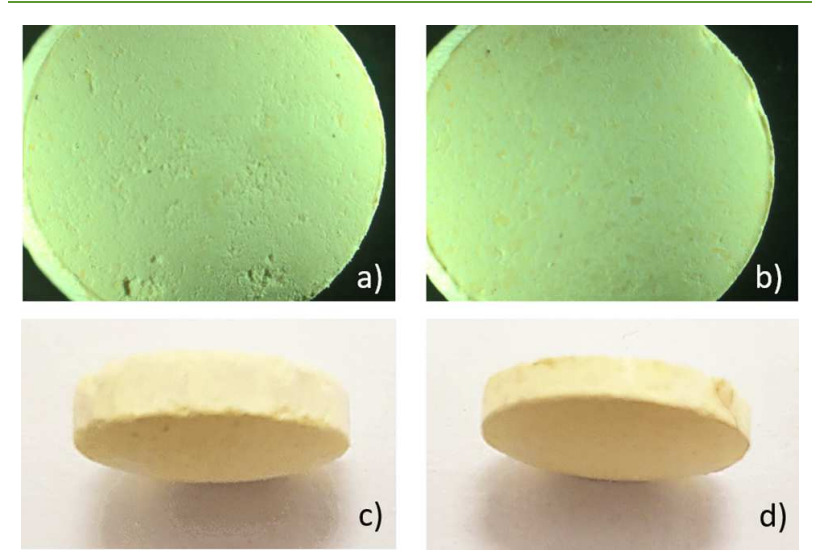

Figure 8. Surface of the tablets prepared by direct tableting of (a) Iplanetary and (b) II-planetary and thickness of the tablets of (c) Iplanetary and (d) II-planetary. All samples were compressed as received without additional mechanical treatment. but depending on the compressibility of the powder, different thickness and hardness were obtained with II having slightly better compressibility (Figure $8 \mathrm{c}$ and $8 \mathrm{~d}$ ). After tableting, both I and II retained their respective solid forms (Figure S19). It can be concluded that both polymorph samples were suitable for direct compression. However, to achieve better quality of the tablets, additional pulverization of the products or the addition of some excipients may be necessary. Molecular sheets that further form layers, which can be found in crystal structures of both I and II (Figure $6 \mathrm{c}$ and $6 \mathrm{~d}$ ), resemble the crystal packing in orthorhombic polymorph of paracetamol. ${ }^{74}$ It was shown how these layers contribute to better compression behavior making orthorhombic polymorph of paracetamol suitable for direct tableting process as well. ${ }^{75}$

\section{CONCLUSION}

We demonstrated here how mechanochemistry enables fast, controllable, and scalable synthesis of polymorphic cocrystals, shown on an FDA-approved pharmaceutical cocrystal of vitamin $\mathrm{C}$ and nicotinamide. State-of-the-art in situ monitoring of milling reactions was used here to detect and capture new polymorph II, thermodynamically more stable when compared to the known form I, and so far accessible exclusively by milling. Selective synthesis and polymorph control were successfully scaled up to $10 \mathrm{-g}$ scale and to flow extrusion processing using different liquid additives and milling conditions. The activity of vitamin $\mathrm{C}$ was not deteriorated by mechanochemical stress or inclusion into a cocrystal, and the cocrystals showed excellent tableting properties. To the best of our knowledge, this is the first example of polymorphic control in a TSE process reported to date. Considering the importance and potential in the pharmaceutical industry that cocrystals gained recently, we believe that examples of large-scale production are necessary to help to implement mechanochemical procedures as green and sustainable manufacturing processes.

\section{ASSOCIATED CONTENT}

Supporting Information

The Supporting Information is available free of charge on the ACS Publications website at DOI: 10.1021/acssuschemeng.9b00043.

Additional PXRD, FTIR-ATR, Raman, and particle size distribution data (PDF)

\section{AUTHOR INFORMATION}

\section{Corresponding Author}

*E-mail: krunoslav.uzarevic@irb.hr.

\section{ORCID}

Tomislav Stolar: 0000-0002-9824-4462

Stipe Lukin: 0000-0003-2247-6803

Ivan Halasz: 0000-0002-5248-4217

Krunoslav Užarević: 0000-0002-7513-6485

\section{Author Contributions}

The manuscript was written by T.S., S.L., I.H., and K.U. All authors have given approval to the final version of the manuscript.

Notes

The authors declare no competing financial interest. 


\section{ACKNOWLEDGMENTS}

S.L. is supported by the Croatian Science Foundation (Grant No. UIP-2014-09-4744). We are grateful to the staff of the 11BM beamline for powder X-ray data collection. Use of the Advanced Photon Source at Argonne National Laboratory was supported by the U.S. Department of Energy, Office of Science, Office of Basic Energy Sciences, under Contract No. DE-AC02-06CH11357.

\section{REFERENCES}

(1) Do, J.-L.; Friščić, T. Mechanochemistry: A Force of Synthesis. ACS Cent. Sci. 2017, 3, 13-19.

(2) James, S. L.; Adams, C. J.; Bolm, C.; Braga, D.; Collier, P.; Frišcić, T.; Grepioni, F.; Harris, K. D. M.; Hyett, G.; Jones, W.; et al. Mechanochemistry: opportunities for new and cleaner synthesis. Chem. Soc. Rev. 2012, 41, 413-447.

(3) Friščić, T. Supramolecular concepts and new techniques in mechanochemistry: cocrystals, cages, rotaxanes, open metal-organic frameworks. Chem. Soc. Rev. 2012, 41, 3493-3510.

(4) Baláž, P.; Achimovičová, M.; Baláž, M.; Billik, P.; CherkezovaZheleva, Z.; Criado, J. M.; Delogu, F.; Dutková, E.; Gaffet, E.; Gotor, F. J.; Kumar, R.; Mitov, I.; Rojac, T.; Senna, M.; Streletskii, A.; Wieczorek-Ciurowa, K. Hallmarks of mechanochemistry: from nanoparticles to technology. Chem. Soc. Rev. 2013, 42, 7571-7637.

(5) Roschangar, F.; Colberg, J.; Dunn, P. J.; Gallou, F.; Hayler, J. D.; Koenig, S. G.; Kopach, M. E.; Leahy, D. K.; Mergelsberg, I.; Tucker, J. L.; Sheldon, R. A.; Senanayake, C. H. A deeper shade of green: inspiring sustainable drug manufacturing. Green Chem. 2017, 19, $281-285$

(6) Friščić, T.; Jones, W. Recent Advances in Understanding the Mechanism of Cocrystal Formation via Grinding. Cryst. Growth Des. 2009, 9, 1621-1637.

(7) Hasa, D.; Jones, W. Screening for new pharmaceutical solid forms using mechanochemistry: A practical guide. Adv. Drug Delivery Rev. 2017, 117, 147-161.

(8) Braga, D.; Maini, L.; Grepioni, F. Mechanochemical preparation of co-crystals. Chem. Soc. Rev. 2013, 42, 7638-7648.

(9) Fleischman, S. G.; Kuduva, S. S.; McMahon, J. A.; Moulton, B.; Bailey Walsh, R. D.; Rodríguez-Hornedo, N.; Zaworotko, M. J. Crystal Engineering of the Composition of Pharmaceutical Phases: Multiple-Component Crystalline Solids Involving Carbamazepine. Cryst. Growth Des. 2003, 3, 909-919.

(10) Tan, D.; Loots, L.; Friščić, T. Towards medicinal mechanochemistry: evolution of milling from pharmaceutical solid form screening to the synthesis of active pharmaceutical ingredients (APIs). Chem. Commun. 2016, 52, 7760-7781.

(11) Colacino, E.; Porcheddu, A.; Halasz, I.; Charnay, C.; Delogu, F.; Guerra, R.; Fullenwarth, J. Mechanochemistry for "no solvent, no base" preparation of hydantoin-based active pharmaceutical ingredients: nitrofurantoin and dantrolene. Green Chem. 2018, 20, 29732977.

(12) Andre, V.; Hardeman, A.; Halasz, I.; Stein, R. S.; Jackson, G. J.; Reid, D. G.; Duer, M. J.; Curfs, C.; Duarte, M. T.; Friščić, T. Mechanosynthesis of the Metallodrug Bismuth Subsalicylate from $\mathrm{Bi}_{2} \mathrm{O}_{3}$ and Structure of Bismuth Salicylate without Auxiliary Organic Ligands. Angew. Chem. 2011, 123, 8004-8007.

(13) Crawford, D. E.; Casaban, J. Recent Developments in Mechanochemical Materials Synthesis by Extrusion. Adv. Mater. 2016, 28, 5747-5754.

(14) Crawford, D. E.; Miskimmin, C. K. G.; Albadarin, A. B.; Walker, G.; James, S. L. Organic synthesis by Twin Screw Extrusion (TSE): continuous, scalable and solvent-free. Green Chem. 2017, 19, 1507-1518.

(15) Cao, Q.; Howard, J. L.; Crawford, D. E.; James, S. L.; Browne, D. L. Translating solid state organic synthesis from a mixer mill to a continuous twin screw extruder. Green Chem. 2018, 20, 4443-4447.

(16) Ardila-Fierro, K. J.; Crawford, D. E.; Körner, A.; James, S. L.; Bolm, C. Hernánder I $C$ Panain-catalyced merhanochemiral synthesis of oligopeptides by milling and twin-screw extrusion: application in the Juliá-Colonna enantioselective epoxidation. Green Chem. 2018, 20, 1262-1269.

(17) Crawford, D. E.; Casaban, J.; Haydon, R.; Giri, N.; McNally, T.; James, S. L. Synthesis by extrusion: continuous, large-scale preparation of MOFs using little or no solvent. Chem. Sci. 2015, 6, $1645-1649$.

(18) Karadeniz, B.; Howarth, A. J.; Stolar, T.; Islamoglu, T.; Dejanović, I.; Tireli, M.; Wasson, M. C.; Moon, S.-Y.; Farha, O. K.; Friščić, T.; Užarević, K. Benign by Design: Green and Scalable Synthesis of Zirconium UiO-Metal-Organic Frameworks by WaterAssisted Mechanochemistry. ACS Sustainable Chem. Eng. 2018, 6, 15841-15849.

(19) Crawford, D. E.; James, S. L.; McNally, T. Use of Batch Mixing To Investigate the Continuous Solvent-Free Mechanical Synthesis of OLED Materials by Twin-Screw Extrusion (TSE). ACS Sustainable Chem. Eng. 2018, 6, 193-201.

(20) Daurio, D.; Nagapudi, K.; Li, L.; Quan, P.; Nunez, F.-A. Application of twin screw extrusion to the manufacture of cocrystals: scale-up of AMG 517-sorbic acid cocrystal production. Faraday Discuss. 2014, 170, 235-249.

(21) Daurio, D.; Medina, C.; Saw, R.; Nagapudi, K.; Alvarez-Núñez, F. Application of Twin Screw Extrusion in the Manufacture of Cocrystals, Part I: Four Case Studies. Pharmaceutics 2011, 3, 582600 .

(22) Medina, C.; Daurio, D.; Nagapudi, K.; Alvarez-Núñez, F. Manufacture of pharmaceutical co crystals using twin screw extrusion: A solvent less and scalable process. J. Pharm. Sci. 2010, 99, 16931696.

(23) Trask, A. V.; Motherwell, W. D. S.; Jones, W. Pharmaceutical Cocrystallization: Engineering a Remedy for Caffeine Hydration. Cryst. Growth Des. 2005, 5, 1013-1021.

(24) Trask, A. V.; Motherwell, W. D. S.; Jones, W. Physical stability enhancement of theophylline via cocrystallization. Int. J. Pharm. 2006, $320,114-123$.

(25) Jones, W.; Motherwell, W.; Trask, A. V. Pharmaceutical Cocrystals: An Emerging Approach to Physical Property Enhancement. MRS Bull. 2006, 31, 875-879.

(26) Karki, S.; Friščić, T.; Fábián, L.; Laity, P. R.; Day, G. M.; Jones, W. Improving Mechanical Properties of Crystalline Solids by Cocrystal Formation: New Compressible Forms of Paracetamol. Adv. Mater. 2009, 21, 3905-3909.

(27) Shiraki, K.; Takata, N.; Takano, R.; Hayashi, Y.; Terada, K. Dissolution improvement and the mechanism of the improvement from cocrystallization of poorly water-soluble compounds. Pharm. Res. 2008, 25, 2581-2592.

(28) McNamara, D. P.; Childs, S. L.; Giordano, J.; Iarriccio, A.; Cassidy, J.; Shet, M. S.; Mannion, R.; O’Donnell, E.; Park, A. Use of a Glutaric Acid Cocrystal to Improve Oral Bioavailability of a Low Solubility API. Pharm. Res. 2006, 23, 1888-1897.

(29) Good, D. J.; Rodríguez-Hornedo, N. Solubility Advantage of Pharmaceutical Cocrystals. Cryst. Growth Des. 2009, 9, 2252-2264.

(30) Babu, N. J.; Nangia, A. Solubility Advantage of Amorphous Drugs and Pharmaceutical Cocrystals. Cryst. Growth Des. 2011, 11, 2662-2679.

(31) Duggirala, N. K.; Perry, M. L.; Almarsson, Ö.; Zaworotko, M. J. Pharmaceutical cocrystals: along the path to improved medicines. Chem. Commun. 2016, 52, 640-655.

(32) Blagden, N.; Coles, S. J.; Berry, D. J. Pharmaceutical co-crystals - are we there yet? CrystEngComm 2014, 16, 5753-5761.

(33) Ross, S. A.; Lamprou, D. A.; Douroumis, D. Engineering and manufacturing of pharmaceutical co-crystals: a review of solvent-free manufacturing technologies. Chem. Commun. 2016, 52, 8772-8786.

(34) U.S. Department of Health and Human Services, Food and Drug Administration, Center for Drug Evaluation and Research (CDER). Regulatory Classification of Pharmaceutical Co-Crystals: Guidance for Industry, February 2018. https://www.fda.gov/ downloads/Drugs/Guidances/UCM281764.pdf.

(25) $\mathrm{httn}$ // / талилат entrectn $\mathrm{rom} / \mathrm{index}$ icn 
(36) Pappenberger, G.; Hohmann, H.-P. Industrial production of Lascorbic Acid (vitamin C) and D-isoascorbic acid. Adv. Biochem. Eng./ Biotechnol. 2013, 143, 143-188.

(37) https://www.accessdata.fda.gov/scripts/cdrh/cfdocs/cfcfr/ CFRSearch.cfm?fr=172.315 (accessed 22/02/2019).

(38) Buu-Hoï, N. P.; Ratsimamanga, A. R.; Xuong, N. D.; NigeonDureuil, M. Study of nicastubine, an addition compound of vitamin PP and vitamin C. Bull. Soc. Chim. Biol. 1953, 35, 326-333.

(39) Stahly, G. P. A Survey of Cocrystals Reported Prior to 2000. Cryst. Growth Des. 2009, 9, 4212-4229.

(40) Bailey, C. W.; Bright, J. R.; Jasper, J. J. A Study of the Binary System Nicotinamide-Ascorbic Acid. J. Am. Chem. Soc. 1945, 67, 1184-1186.

(41) Fox, S. H.; Paterson, O. L. U.S. Patent US2433688A, 1943.

(42) Wenner, W. The reaction of $L$-ascorbic and $D$-isoascorbic acid with nicotinic acid and its amide. J. Org. Chem. 1949, 14, 22-26.

(43) Wang, J.-R.; Bao, J.; Fan, X.; Dai, W.; Mei, X. pH-Switchable vitamin $\mathrm{B}_{9}$ gels for stoichiometry-controlled spherical co-crystallization. Chem. Commun. 2016, 52, 13452-13455.

(44) Frišcić, T.; Halasz, I.; Beldon, P. J.; Belenguer, A. M.; Adams, F.; Kimber, S. A. J.; Honkimaki, V.; Dinnebier, R. E. Real-time and in situ monitoring of mechanochemical milling reactions. Nat. Chem. 2013, 5, 66-73.

(45) Halasz, I.; Puškarić, A.; Kimber, S. A. J.; Beldon, P. J.; Belenguer, A. M.; Adams, F.; Honkimäki, V.; Dinnebier, R. E.; Patel, B.; Jones, W.; Strukil, V.; Friščí, T. Real Time In Situ Powder X ray Diffraction Monitoring of Mechanochemical Synthesis of Pharmaceutical Cocrystals. Angew. Chem., Int. Ed. 2013, 52, 11538-11541.

(46) Batzdorf, L.; Fischer, F.; Wilke, M.; Wenzel, K. J.; Emmerling, F. Direct In Situ Investigation of Milling Reactions Using Combined $\mathrm{X}$ ray Diffraction and Raman Spectroscopy. Angew. Chem., Int. Ed. 2015, 54, 1799-1802.

(47) Katsenis, A. D.; Puškarić, A.; Štrukil, V.; Mottillo, C.; Julien, P. A.; Užarević, K.; Pham, M.-H.; Do, T.-O.; Kimber, S. A. J.; Lazić, P.; Magdysyuk, O.; Dinnebier, R. E.; Halasz, I.; Friščić, T. In situ X-ray diffraction monitoring of a mechanochemical reaction reveals a unique topology metal-organic framework. Nat. Commun. 2015, 6, 6662.

(48) Užarević, K.; Halasz, I.; Friščić, T. Real-Time and In Situ Monitoring of Mechanochemical Reactions: A New Playground for All Chemists. J. Phys. Chem. Lett. 2015, 6, 4129-4140.

(49) Julien, P. A.; Užarević, K.; Katsenis, A. D.; Kimber, S. A. J.; Wang, T.; Farha, O. K.; Zhang, Y.; Casaban, J.; Germann, L. S.; Etter, M.; Dinnebier, R. E.; James, S. L.; Halasz, I.; Friščić, T. In Situ Monitoring and Mechanism of the Mechanochemical Formation of a Microporous MOF-74 Framework. J. Am. Chem. Soc. 2016, 138, 2929-2932.

(50) Michalchuk, A. A. L.; Tumanov, I. A.; Konar, S.; Kimber, S. A. J.; Pulham, C. R.; Boldyreva, E. V. Challenges of Mechanochemistry: Is In Situ Real Time Quantitative Phase Analysis Always Reliable? A Case Study of Organic Salt Formation. Adv. Sci. 2017, 4, 1700132.

(51) Kulla, H.; Haferkamp, S.; Akhmetova, I.; Röllig, M.; Maierhofer, C.; Rademann, K.; Emmerling, F. In Situ Investigations of Mechanochemical One Pot Syntheses. Angew. Chem., Int. Ed. 2018, 57, 5930-5933.

(52) Wilke, M.; Casati, N. Insight into the Mechanochemical Synthesis and Structural Evolution of Hybrid Organic-Inorganic Guanidinium Lead(II) Iodides. Chem. - Eur. J. 2018, 24, 17701.

(53) Stolar, T.; Batzdorf, L.; Lukin, S.; Žilić, D.; Motillo, C.; Friščíc, T.; Emmerling, F.; Halasz, I.; Užarević, K. In Situ Monitoring of the Mechanosynthesis of the Archetypal Metal-Organic Framework HKUST-1: Effect of Liquid Additives on the Milling Reactivity. Inorg. Chem. 2017, 56, 6599-6608.

(54) Gracin, D.; Strukil, V.; Friščić, T.; Halasz, I.; Užarević, K. Laboratory Real Time and In Situ Monitoring of Mechanochemical Milling Reactions by Raman Spectroscopy. Angew. Chem., Int. Ed. 2014, 53, 6193-6197.

(55) Kawashima, Y.; Imai, M.; Takeuchi, H.; Yamamoto, H.; Kamiya, K.; Hino, T. Improved flowability and compactibility of spherically agglomerated crystals of ascorbic acid for direct tableting designed by spherical crystallization process. Powder Technol. 2003, 130, 283-289.

(56) Urabe, M.; Ito, S.; Itai, S.; Yuasa, H.; Kanaya, Y. Assessment of tableting properties using infinitesimal quantities of powdered medicine. Int. J. Pharm. 2003, 263, 183-187.

(57) Urabe, M.; Ito, S.; Itai, S.; Yuasa, H. Assessment of tableting properties using infinitesimal quantities of powder medicine II. J. Drug Delivery Sci. Technol. 2006, 16, 357-361.

(58) Filimonova, A. V.; Tret'yakova, Y. A.; Gavrilov, A. S. 3Dmodeling of the influence of isomalt, glucose, and compaction pressure on the quality of ascorbic-acid tablets. Pharm. Chem. J. 2018, $52,467-472$.

(59) Milardović, S.; Kereković, I.; Derrico, R.; Rumenjak, V. A novel method for flow injection analysis of total antioxidant capacity using enzymatically produced ABTS*+ and biamperometric detector containing interdigitated electrode. Talanta 2007, 71, 213-220.

(60) Lukin, S.; Stolar, T.; Tireli, M.; Blanco, M. V.; Babić, D.; Frišcić, T.; Užarević, K.; Halasz, I. Tandem in Situ Monitoring for Quantitative Assessment of Mechanochemical Reactions Involving Structurally Unknown Phases. Chem. - Eur. J. 2017, 23, 13941-13949.

(61) Jaumot, J.; de Juan, J.; Tauler, R. MCR-ALS GUI 2.0: new features and applications. Chemom. Intell. Lab. Syst. 2015, 140, 1-12.

(62) de Juan, A.; Jaumot, J.; Tauler, R. Multivariate Curve Resolution (MCR). Solving the mixture analysis problem. Anal. Methods 2014, 6, 4964-4976.

(63) Shan, N.; Toda, F.; Jones, W. Mechanochemistry and co-crystal formation: effect of solvent on reaction kinetics. Chem. Commun. 2002, 0, 2372-2373.

(64) Trask, A. V.; Motherwell, W. D. S.; Jones, W. Solvent-drop grinding: green polymorph control of cocrystallisation. Chem. Commun. 2004, 0, 890-891.

(65) Friščić, T.; Trask, A. V.; Jones, W.; Motherwell, W. D. S. Screening for Inclusion Compounds and Systematic Construction of Three Component Solids by Liquid Assisted Grinding. Angew. Chem., Int. Ed. 2006, 45, 7546-7550.

(66) Hasa, D.; Miniussi, E.; Jones, W. Mechanochemical Synthesis of Multicomponent Crystals: One Liquid for One Polymorph? A Myth to Dispel. Cryst. Growth Des. 2016, 16, 4582-4588.

(67) Belenguer, A. M.; Lampronti, G. I.; De Mitri, N.; Driver, M.; Hunter, C. A.; Sanders, J. K. M. Understanding the influence of surface solvation and structure on polymorph stability: a combined mechanochemical and theoretical approach. J. Am. Chem. Soc. 2018, 140, 17051-17059.

(68) Etter, M. C.; MacDonald, J. C.; Bernstein, J. Graph-set analysis of hydrogen-bond patterns in organic crystals. Acta Crystallogr., Sect. B: Struct. Sci. 1990, B46, 256-262.

(69) Bag, P. P.; Patni, M.; Malla Reddy, C. A kinetically controlled crystallization process for identifying new co-crystal forms: fast evaporation of solvent from solutions to dryness. CrystEngComm 2011, 13, 5650-5652.

(70) Ostwald, W. Studien über die Bildung und Umwandlung fester Körper. Z. Phys. Chem. 1897, 22, 289-330.

(71) Miller, N. J.; Rice-Evans, C.; Davies, M. J.; Gopinathan, V.; Milner, A. A Novel Method for Measuring Antioxidant Capacity and its Application to Monitoring the Antioxidant Status in Premature Neonates. Clin. Sci. 1993, 84, 407-412.

(72) Re, R.; Pellegrini, N.; Proteggente, A.; Pannala, A.; Yang, M.; Rice-Evans, C. Antioxidant activity applying an improved ABTS radical cation decolorization assay. Free Radical Biol. Med. 1999, 26, 1231-1237.

(73) Han, X.; Ghoroi, C.; To, D.; Chen, Y.; Davé, R. Simultaneous micronization and surface modification for improvement of flow and dissolution of drug particles. Int. J. Pharm. 2011, 415, 185-195.

(74) Bučar, D.-K.; Elliott, J. A.; Eddleston, M. D.; Cockcroft, J. K.; Jones, W. Sonocrystallization Yields Monoclinic Paracetamol with Significantly Improved Compaction Behavior. Angew. Chem., Int. Ed. 2015, 54, 249-253. 
(75) Joiris, E.; Martino, P. D.; Berneron, C.; Guyot-Hermann, A.-M.; Guyot, J.-C. Compression Behavior of Orthorhombic Paracetamol.

Pharm. Res. 1998, 15, 1122-1130. 